\section{$\underset{\substack{\text { hommes } \\ \text { \& migrations }}}{ }$}

\section{Hommes \& migrations}

Revue française de référence sur les dynamiques

migratoires

$1322 \mid 2018$

Exposer les migrations

\title{
Un défi de démocratie culturelle
}

\section{Marie Poinsot}

\section{CpenEdition \\ Journals}

\section{Édition électronique}

URL : https://journals.openedition.org/hommesmigrations/6563

DOI : 10.4000/hommesmigrations.6563

ISSN : 2262-3353

\section{Éditeur}

Musée national de l'histoire de l'immigration

\section{Édition imprimée}

Date de publication : 1 juillet 2018

Pagination : 1

ISBN : 978-2-919040-42-1

ISSN : $1142-852 X$

\section{Référence électronique}

Marie Poinsot, « Un défi de démocratie culturelle », Hommes \& migrations [En ligne], 1322 | 2018, mis en ligne le 01 juillet 2018, consulté le 21 janvier 2022. URL : http://journals.openedition.org/ hommesmigrations/6563; DOI : https://doi.org/10.4000/hommesmigrations.6563 


\section{UN DÉFI DE DÉMOCRATIE CULTURELLE}

Par MARIE POINSOT, rédactrice en chef.

En pleine réflexion du Musée national de l'histoire de l'immigration sur son périmètre scientifique, sur la muséographie et sur la scénographie de ses galeries permanentes, la revue propose un inventaire des recherches coordonnées dans plusieurs régions sur les processus de patrimonialisation de l'immigration. La prise en compte régionale ou locale de l'immigration bouscule en effet les musées, tant les enjeux sociaux et politiques afférents interpellent leurs codes et les démarches professionnelles.

Ce dossier complète des travaux menés par le musée sur les "Dynamiques territoriales des acteurs de l'histoire et des mémoires de l'immigration » (Mikael Petitjean, 2013), sur « La recherche sur les migrations et l'immigration. Un état des lieux» (mars 2017), et, plus récemment, les réflexions des Assises nationales du réseau d'acteurs du Musée national de l'histoire de l'immigration (octobre 2017) dont une synthèse est présentée dans ce numéro. La lecture des articles permet d'apprécier l'effet de levier suscité par la création du musée qui a servi à légitimer une thématique marginalisée dans le secteur culturel. Ainsi, chaque article relate une expérience menée en France, depuis les années 1980 jusqu'à nos jours, pour rendre visible et valoriser la contribution de l'histoire de l'immigration dans les histoires des territoires concernés. Ces expériences sont autant de laboratoires qui interrogent les modalités intellectuelles, pratiques et symboliques des collectes et des écritures plurielles d'une histoire de l'immigration.

La question de la fabrication des patrimoines est centrale et permet des comparaisons. Les motivations particulières des acteurs selon leur profil et leur contribution (conservateurs, archivistes, chercheurs, médiateurs, acteurs associatifs, etc.) influencent les modalités de prises de décision, les étapes de conception et la méthodologie des projets. Il apparaît difficile de mobiliser la participation des populations immigrées ou les jeunes générations quand la démarche de collecte d'objets, d'archives ou de récits est descendante, partielle, et qu'elle ne prend pas en compte les aspirations profondes, les compétences et les savoir-faire de ceux qui sont sollicités pour témoigner et écrire «leur histoire».

En matière d'écriture des récits de vie, il s'avère que la fiction inspirée par des itinéraires personnels permet parfois de garantir l'anonymat et d'apporter une charge émotive aux "savoirs expérientiels». La photographie, quant à elle, présente une trace de l'instant, celui provoqué par le déclic du photographe. Cependant, son insertion dans le musée lui attribue une qualité de permanence parfois source de malentendus. Elle doit donc être interrogée par une lecture contextualisée à la fois sémiologique, narrative et esthétique.

«Exposer les migrations » engage les musées dans le débat sur la démocratie culturelle. L'immigration comme thème de collection pose un double enjeu : la représentation et la reconnaissance des mobilités, des cultures, des identités reflétant la sociologie des territoires; la participation active, sans injonction, d'une pluralité d'acteurs qui mutualisent leurs ressources dans un projet collaboratif commun et citoyen. La place de l'artiste et de la création contemporaine s'insère dans cette réflexion sur de nouvelles formes de muséographie, davantage pluridisciplinaires. La médiation, incontournable pour mobiliser les publics éloignés de la culture, interroge les relations de l'institution patrimoniale ou culturelle avec son environnement. Certains musées profitent de la fermeture pour travaux de leurs salles permanentes pour inciter leurs équipes à accompagner des expositions itinérantes qui participent à l'irrigation culturelle de leur territoire ; une sorte d'exploration hors les murs qui se frotte aux réalités évolutives des populations. Dans ce sens, les musées reflètent les mouvements du monde en réhabilitant la dimension internationale du passé, le cosmopolitisme des histoires singulières, les mémoires des espaces inclusifs ou exclusifs, selon les périodes de notre histoire commune. 